\title{
Continuity and change in sporting and leisure time physical activities during adolescence
}

\author{
S M Dovey, A I Reeder, D J Chalmers
}

\begin{abstract}
Objectives-To map the pattern of involvement in physical activities by adolescents at ages 15 and 18 years.

Methods-Data from a longitudinal cohort study were used. Participants in the Dunedin Multidisciplinary Health and Development Study provided information about their sporting and similar physical activities during the 12 months before study assessments at ages 15 and 18 years. Results-Total participation time at age 18 was $63 \%$ of that reported at age 15 . Mean participation time for girls decreased from 7.5 hours a week to 4.3 hours a week $(p<0.001)$ whereas for boys it decreased from 11.7 hours a week to 7.8 hours a week $(p<0.001)$. At both ages, boys spent significantly more time in physical activity than girls. More time in physical activity at age 18 was reported by participants who judged their fitness higher than their peers (odds ratio (OR) 1.7: 1.2, 2.5), those who played sport for their school (OR 1.8: 1.3, 2.4), and those reporting very good self assessed health (OR 1.4: 1.0, 1.8) at age 15. The overall median number of activities decreased from seven at age 15 to three at 18. Boys were involved in more activities at age 15 but there was no sex difference at age 18 in the number of different activities reported.
\end{abstract}

Conclusion-Although involvement in school sporting activities and high levels of fitness in mid-adolescence may protect against marked reductions in physical activity in late adolescence, social and organisational factors are also likely to be important. There is a need for innovative approaches to health promotion which will encourage adolescents to maintain higher levels of physical activity after they leave school.

(Br f Sports Med 1998;32:53-57)

Preventive and Social

Medicine, Otago

Medical School, PO

Box 913, Dunedin, New

Zealand

S M Dovey

A I Reeder

D J Chalmers

Correspondence to: Ms Susan Dovey,

Department of General

Practice, Dunedin School of

Medicine, University of

Otago, PO Box 913

Dunedin, New Zealand.

Accepted for publication 19 November 1997
Keywords: physical activity; adolescence; leisure activities; longitudinal studies

In economically developed societies like New Zealand, increased prevalence of the "diseases of affluence" has been linked with sedentary lifestyles resulting from a reduced need for physical exertion in work, recreation, and transport. Increased leisure time physical activity is an effective means of counteracting some of the negative effects of modern lifestyles. Among adults, there is evidence that regular exercise helps to prevent heart disease, ${ }^{12}$ non-insulin-dependent diabetes mellitus, ${ }^{3}$ some cancers, ${ }^{4-6}$ osteoporosis, ${ }^{7}$ and depression. ${ }^{8}$ In community based studies, it is consistently associated with better self assessed health. ${ }^{9-11}$ Membership in a sports club is related to better overall health for children, ${ }^{12}$ and exercise programmes in the school curriculum can improve fitness and lower blood pressure and serum lipid levels. ${ }^{13}$ Involvement in sports activities in youth is also associated with greater involvement in organised sport in adulthood. ${ }^{14}$

Adolescents constitute nearly one fifth of New Zealand's population. By most measures they are healthy: injury is the main cause of death, and acute infections and injury are the main causes of morbidity. ${ }^{15}$ In midadolescence, adult patterns of health behaviour start to emerge; girls begin to report more health problems than boys, ${ }^{16}{ }^{17}$ and other health related measures may also change, including involvement in physical activity, although this effect is not well reported in the literature.

Physical activity habits established in youth may have long term health implications, yet there is a lack of data from longitudinal studies about physical activity during adolescence. Most studies of physical activity among adolescents involve school age populations and are concerned with descriptive epidemiology, establishing participation rates, ${ }^{18}$ or exploring cross sectional associations with other behaviours. ${ }^{19}$ We could find no longitudinal studies of changes in the nature and extent of participation in physical activity as adolescents progress from school to higher education or work.

This paper presents data obtained as part of a broader longitudinal study of health and development. In order to identify possible targets for health promotion interventions, the main aim was to determine whether, between ages 15 and 18 years, there were changes in the time spent in physical activity and in preferred sports. A further aim was to document sex differences in participation in physical activities and determine whether these increased or decreased from mid to late adolescence.

\section{Method}

THE STUDY COHORT

Participants in this study were all members of a birth cohort enrolled in the Dunedin Multidisciplinary Health and Development Study (DMHDS), a longitudinal study of health, development, attitudes, and behaviour described fully elsewhere. ${ }^{20}$ In summary, study participants were born at the Queen Mary Maternity Hospital in Dunedin between 1 April 1972 and 31 March 1973 to mothers 


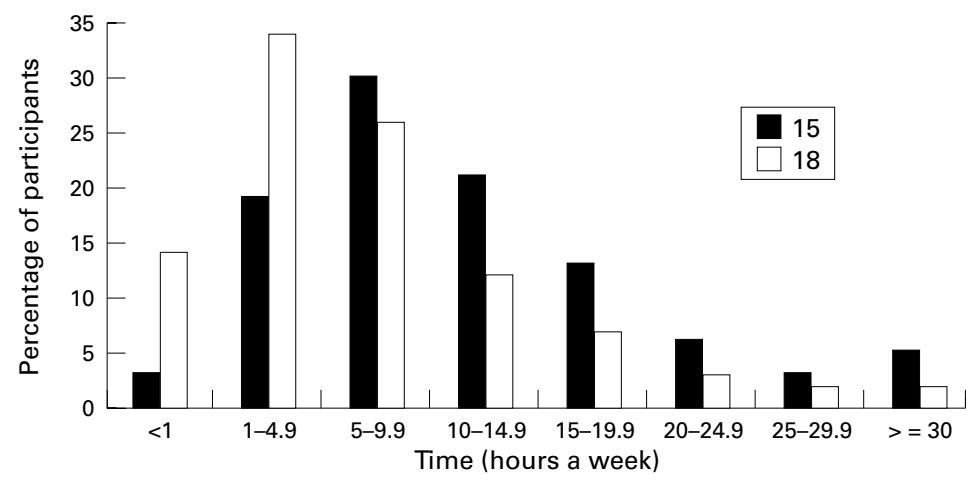

Figure 1 Time spent in physical activity by boys aged 15 and 18 .

residing in the Dunedin area. Of the 1661 live births during this period, 1139 children were still resident in the Otago province on their third birthday and therefore eligible for inclusion in the DMHDS; of these, 1037 were followed up. Cohort members were assessed every two years thereafter until age 15 and then at ages 18 and 21 . The data used for the present study were collected during 19871988 (age 15) and 1990-1991 (age 18). By the time of the interview at age 18, most participants $(73 \%)$ had left school.

The DMHDS cohort is somewhat biased socioeconomically towards the advantaged and ethnically towards those of European descent, although the full socioeconomic spectrum is represented. ${ }^{21}$ By age 15, there had been eight known deaths among cohort members and two further deaths occurred between 15 and 18 years. Severe developmental or intellectual disability prevented the full participation of seven adolescents at age 15 and five at age 18 . At age 15,33 refused to participate, 11 were not seen for reasons such as being out of the country, and nine could not be traced. At age 18, 13 refused to participate, and four could not be traced. Data used in the present study were collected during 1987-1988 (age 15) and 1990-1991 (age 18) when follow up rates of 95 and $97 \%$ of those still living were achieved. This analysis is based on the 775 participants

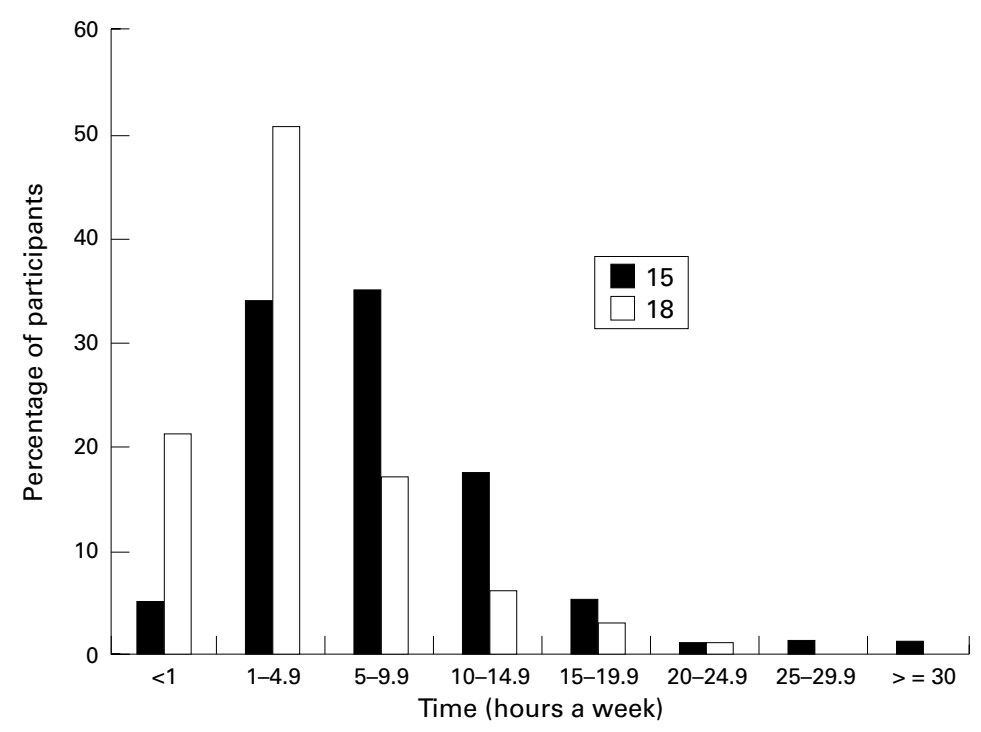

Figure 2 Time spent in physical activity by girls aged 15 and 18. from whom complete physical activity data were available at both assessments (400 boys and 375 girls).

PROCEDURES

Most data were collected from face to face interviews at the Multidisciplinary Health and Development Unit in Dunedin. Before assessments at age 15, written consent was obtained from cohort members and their parents. At 18, consent was obtained from cohort members alone. At both ages confidentiality was assured. As far as possible, interviews were scheduled within two months of participants' birthdays.

The Minnesota Leisure Time Physical Activity Questionnaire ${ }^{22}$ was used at both assessments, modified as described elsewhere. ${ }^{18}$ In summary, participants were asked to recall, for each month of the previous year, the sports and similar physical activities in which they had participated, the number of times they had been involved in each activity, and the amount of participation time on each occasion. Activities included those undertaken as part of school programmes, competitive sports, and leisure time activities undertaken for exercise or recreation. Participation time included time involved in physical training for an activity but specifically excluded time spent socialising afterwards. Variables investigated as predictors of increased physical activity at age 18 were "very good" self assessed health at age 15 (rather than "good", "fair", or "poor"), playing sport in a school team at age 15 (yes/no), and reporting their fitness to be "better" than that of their peers (rather than "the same" or "worse").

Proportions of participants reporting participation times of less than one hour a week, one to four hours a week, and more than four hours a week were compared at ages 15 and 18 using the $\chi^{2}$ test. These boundaries were chosen to assist comparability with other studies, and because of the recommendation at the time of data collection that adults should spend at least 20 minutes in physical activity three times a week. ${ }^{23}$ The non-parametric Wilcoxon matched pairs sign rank test was used to compare activity time and numbers of activities in which individuals participated at each age. A repeated measures analysis of variance was used to study differences between ages and between sexes in both the number of physical activities and participation times. Predictors of more than four hours a week physical activity at age 18 were identified by logistic regression analysis. A 5\% level of significance was used throughout the study.

\section{Results}

Among the 775 study participants for whom physical activity data were available at both study assessments, there was a $37 \%$ reduction in total time spent in physical activity from 390717 hours at age 15 to 245646 hours at age 18 . The overall mean time per week spent in physical activity at age 15 was 9.7 hours, significantly more than the 6.1 hours of mean activity time reported at age $18(\mathrm{p}<0.001)$. 
Table 1 Continuity and change in numbers (\%) of boys and girls reporting different levels of physical activity participation time per week

\begin{tabular}{|c|c|c|c|c|}
\hline & \multicolumn{3}{|c|}{$\begin{array}{l}\text { Hours/week spent in physical activity at } \\
\text { age } 15\end{array}$} & \multirow[b]{2}{*}{ Total at age 18} \\
\hline & $<1$ & $1-4$ & $>4$ & \\
\hline \multicolumn{5}{|l|}{ Boys } \\
\hline \multicolumn{5}{|c|}{ Hours/week spent in physical activity at age 18} \\
\hline$<1$ & $6(1.5)$ & $12(3.0)$ & $32(8.0)$ & $50(12.5)$ \\
\hline $1-4$ & $2(0.5)$ & $16(4.0)$ & $70(17.5)$ & $88(22.0)$ \\
\hline$>4$ & $3(0.8)$ & $23(5.8)$ & $236(59.0)$ & $262(65.5)$ \\
\hline Total at age 15 & $11(2.8)$ & $51(12.8)$ & $338(84.5)$ & $400(100.0)$ \\
\hline \multicolumn{5}{|l|}{ Girls } \\
\hline \multicolumn{5}{|c|}{ Hours/week spent in physical activity at age 18} \\
\hline$<1$ & $7(1.9)$ & $30(8.0)$ & $38(10.0)$ & $75(20.0)$ \\
\hline $1-4$ & $6(1.6)$ & $52(13.9)$ & $104(27.7)$ & $162(43.2)$ \\
\hline$>4$ & $4(1.1)$ & $19(5.1)$ & $115(30.7)$ & $138(36.8)$ \\
\hline Total at age 15 & $17(4.5)$ & $101(26.9)$ & $257(68.5)$ & $375(100.0)$ \\
\hline
\end{tabular}

These changes in total physical activity time and mean hours per week were characteristic of both sexes, although there was continuity between the assessments in the finding that at both ages boys spent significantly more time in physical activity than girls. Boys at age 15 spent a mean of 11.7 hours a week in physical activity, compared with 7.5 hours a week for girls. At age 18 boys reported a mean of 7.8 hours a week in physical activity compared with 4.3 hours a week for girls. Repeated measures analysis of variance showed a significant difference between the sexes in the amount of time spent in physical activity at both ages $(\mathrm{p}<0.001)$, but there was no sex by time interaction ( $p=0.257$ ), suggesting that time reductions were of similar magnitude for both sexes. Figures 1 and 2 show the distributions of activity times in hours per week for boys and girls at both ages.
The proportion of adolescents participating in more than four hours of physical activities a week declined in boys from 84.5 to $65.5 \%$ $(\mathrm{p}<0.001)$ and in girls from 68.5 to $36.8 \%$ $(\mathrm{p}<0.001)$ (table 1). Although $55.8 \%$ of participants remained within the same broad categories of total activity time at both study assessments, tracking was stronger in boys than girls $(64.5 \%$ of boys and $46.5 \%$ of girls reported similar participation times at 15 and 18 years; $p<0.001)$. After accounting for sex differences in the amount of time spent in physical activity, predictors from age 15 of spending more than four hours a week in physical activity at age 18 were having very good self assessed health (odds ratio $(\mathrm{OR})=$ $1.4: 1.0,1.8)$, playing sport in a school team $(\mathrm{OR}=1.8: 1.3,2.4)$, and judging one's own fitness to be better than one's peers $(O R=1.7$ : $1.2,2.5)$. When this analysis was conducted for each group separately, the significant predictors of spending more than four hours a week in physical activity at 18 for boys were playing representative sport at age $15(\mathrm{OR}=2.1: 1.3$, 3.2) and having better self assessed fitness (OR $=1.7: 1.0,2.7$ ), whereas for girls, having better self assessed fitness was the only significant predictor $(\mathrm{OR}=1.8: 1.0,3.0)$.

The median number of activities individuals were involved in at age 15 was seven and at age 18, three. Non-parametric tests comparing matched data for individuals showed that $86 \%$ of girls $(\mathrm{N}=322)$ and $86 \%$ of boys $(\mathrm{N}=343)$ decreased the number of different activities in which they were involved and only $7 \%(\mathrm{~N}=$ 57 ) increased their number of activities be-

Table 2 Changes from ages 15 to 18 in physical activity participation rates and proportion of total time spent in different activities ( $N=400$ for boys, $N=375$ for girls)

\begin{tabular}{|c|c|c|c|c|c|c|c|}
\hline \multirow[b]{2}{*}{ Activity } & & \multicolumn{3}{|c|}{ Participation rate (\% of study group) } & \multicolumn{3}{|c|}{ Participation rate (\% of total time) } \\
\hline & & Age 15 & Age 18 & Difference $(95 \%$ CI) & Age 15 & Age 18 & Difference $(95 \%$ CI) \\
\hline \multirow[t]{2}{*}{ Cycling } & M & 48 & 23 & 25 (18.6 to 31.4$)$ & 13 & 10 & $3(2.0$ to 4.9$)$ \\
\hline & $\mathrm{F}$ & 39 & 24 & $15(8.4$ to 21.5$)$ & 9 & 10 & $-1(-2.9$ to 0.7$)$ \\
\hline \multirow[t]{2}{*}{ Swimming } & $M$ & 50 & 15 & $35(29.0$ to 41.0$)$ & 6 & 4 & $2(1.8$ to 3.8$)$ \\
\hline & $\mathrm{F}$ & 57 & 30 & 27 (20.1 to 33.8$)$ & 10 & 7 & $3(0.7$ to 4.1$)$ \\
\hline \multirow[t]{2}{*}{ Rugby } & $M$ & 50 & 27 & $23(16.4$ to 29.6$)$ & 5 & 8 & $-3(-4.7$ to -2.4$)$ \\
\hline & $\mathrm{F}$ & 5 & 8 & $-3(-6.5$ to 0.6$)$ & 0 & 1 & $-1(-1.5$ to -0.4$)$ \\
\hline \multirow[t]{2}{*}{ Skiing } & $M$ & 23 & 18 & $5(-0.6$ to 10.6$)$ & 2 & 3 & $-1(-1.7$ to -0.2$)$ \\
\hline & $\mathrm{F}$ & 26 & 18 & $8(2.1$ to 13.9$)$ & 4 & 5 & $-1(-2.1$ to 0.4$)$ \\
\hline \multirow[t]{2}{*}{ Run/jogging } & M & 37 & 16 & 21 (15.1 to 26.9$)$ & 5 & 3 & $2(1.0$ to 2.8$)$ \\
\hline & $\mathrm{F}$ & 34 & 14 & $20(14.0$ to 26.0$)$ & 4 & 5 & $-1(-2.6$ to -0.0$)$ \\
\hline \multirow[t]{2}{*}{ Tennis } & M & 33 & 15 & $18(12.2$ to 23.8$)$ & 3 & 3 & $0(-0.4$ to 1.1$)$ \\
\hline & $\mathrm{F}$ & 33 & 16 & $17(11.0$ to 23.1$)$ & 4 & 3 & $1(-1.0$ to 1.2$)$ \\
\hline \multirow{2}{*}{ Walking } & M & 15 & 9 & $6(1.5$ to 10.5$)$ & 5 & 5 & $0(-1.5$ to 0.5$)$ \\
\hline & $\mathrm{F}$ & 25 & 21 & $4(-2.0$ to 10.0$)$ & 10 & 12 & $-2(-3.3$ to 0.5$)$ \\
\hline \multirow{2}{*}{ Netball } & $M$ & 0 & 2 & $-2(-3.2$ to -0.3$)$ & 0 & 0 & $0(-0.1$ to 0.1$)$ \\
\hline & $\mathrm{F}$ & 43 & 24 & 19 (12.3 to 25.6$)$ & 4 & 5 & $-1(-2.7$ to -0.1$)$ \\
\hline \multirow[t]{2}{*}{ Volleyball } & M & 29 & 13 & $16(10.5$ to 21.5$)$ & 2 & 2 & $0(-0.6$ to 0.8$)$ \\
\hline & $\mathrm{F}$ & 24 & 8 & $16(10.9$ to 21.1$)$ & 3 & 3 & $0(-0.8$ to 1.2$)$ \\
\hline \multirow[t]{2}{*}{ Cricket } & M & 49 & 17 & $32(25.9$ to 38.1$)$ & 8 & 6 & $2(1.0$ to 3.2$)$ \\
\hline & $\mathrm{F}$ & 16 & 4 & $12(7.8$ to 16.2$)$ & 1 & 1 & $0(-0.6$ to 0.8$)$ \\
\hline \multirow[t]{2}{*}{ Soccer } & M & 35 & 15 & $20(14.2$ to 25.8$)$ & 3 & 4 & $-1(-2.0$ to -0.3$)$ \\
\hline & $\mathrm{F}$ & 6 & 5 & $1(-2.2$ to 4.4$)$ & 1 & 1 & $0(-1.3$ to -0.1$)$ \\
\hline \multirow{2}{*}{ Surfing } & M & 15 & 11 & $4(-0.7$ to 8.7$)$ & 3 & 3 & $0(-0.6$ to 0.9$)$ \\
\hline & $\mathrm{F}$ & 3 & 2 & $1(-1.5$ to 3.1$)$ & 1 & 2 & $-1(-2.0$ to -0.6$)$ \\
\hline \multirow[t]{2}{*}{ Fishing } & $M$ & 36 & 11 & $25(19.4$ to 30.6$)$ & 5 & 4 & $1(0.8$ to 2.7$)$ \\
\hline & $\mathrm{F}$ & 9 & 3 & $6(2.8$ to 9.5$)$ & 1 & 1 & $0(-0.4$ to 0.8$)$ \\
\hline \multirow[t]{2}{*}{ Tramping } & $M$ & 26 & 9 & $17(11.9$ to 22.1$)$ & 2 & 2 & $0(0.2$ to 1.4$)$ \\
\hline & $\mathrm{F}$ & 16 & 5 & $11(6.6$ to 15.3$)$ & 1 & 2 & $-1(-1.4$ to 0.3$)$ \\
\hline \multirow[t]{2}{*}{ Motorcycling } & M & 12 & 12 & $0(-4.5$ to 4.5$)$ & 3 & 4 & $-1(-2.0$ to -0.3$)$ \\
\hline & $\mathrm{F}$ & 3 & 1 & $2(-0.1$ to 4.0$)$ & 0 & 0 & $0(-0.4$ to 0.5$)$ \\
\hline \multirow[t]{2}{*}{ Squash } & M & 24 & 6 & 18 (13.2 to 22.8$)$ & 2 & 1 & $1(0.4$ to 1.5$)$ \\
\hline & $\mathrm{F}$ & 6 & 6 & $0(-3.4$ to 3.4$)$ & 1 & 1 & $0(-1.0$ to 0.4$)$ \\
\hline \multirow{2}{*}{ Golf } & M & 18 & 11 & $7(2.1$ to 11.9$)$ & 3 & 3 & $0(-1.1$ to 0.5$)$ \\
\hline & $\mathrm{F}$ & 2 & 0 & $2(0.3$ to 3.4$)$ & 0 & 0 & $0(-0.1$ to 0.1$)$ \\
\hline
\end{tabular}

M, male; F, female; CI, confidence interval. 
tween study assessments. There was no significant difference between boys and girls in the changing number of activities reported from ages 15 to 18 . For girls, the median number of activities decreased from six to three, and for boys, from seven to three.

In table 2, the most popular physical activities are ranked according to the proportions of the cohort participating at age 18 . Motorcycling was the only activity that had a consistent rate of participation at both assessments and for both sexes. The general pattern was for participation rates to decrease; there was no significant increase for any activity. However, from ages 15 to 18 the proportion of total time spent in rugby, soccer, and skiing increased for boys, and the proportion of total time spent in rugby, surfing, and netball increased for girls.

\section{Discussion}

Time spent in physical activity is a behavioural factor which has important long term health consequences. Among adolescents exercise is ranked ahead of diet, smoking, and sleep as their most important health concern. ${ }^{24}$ Even so, there is relatively little epidemiological research in the area, and limited data are available about changes in participation in physical activity during adolescence.

Longitudinal studies offer two major advantages over cross sectional investigations. Firstly, they allow examination of the "natural history" of participation in physical activities and secondly, they provide information that enables cohort effects to be distinguished from aging effects. In a series of cross sectional studies involving different people, it is possible that any observed changes are due to differences in participant characteristics alone, rather than to real changes over time. In this study, as the same people were involved at both assessments, our findings of change in physical activity participation from mid to late adolescence are clearly aging effects: that is, they are likely to be found among other groups of teenagers as they grow through adolescence. This knowledge is important in informing health promotion decisions.

Patterns of physical activity involvement from ages 15 to 18 in this study were characterised by change rather than continuity. However, there were three areas where continuity was observed: (a) in gender differences, with girls at both ages reporting significantly less participation time than boys; (b) in the types of activity that were most popular; (c) in the sex association of activities such as rugby, netball, cricket, soccer, surfing, fishing, motorcycling, and golf. Reeder $e t a l^{18}$ suggested that the less physical activity participation by girls at age 15 might “... reflect a tradition of male dominance in sports and similar physical activities in New Zealand". A fuller explanation is offered by the Life in New Zealand (LINZ) study. ${ }^{25}$ This survey involving a probability sample of New Zealanders found that, for women, art and craft activities were more popular leisure time occupations than sport, while for men, the reverse was true. Less participation in physical activity among girls than boys is consistent with the findings of most US and Canadian studies reviewed by Stephens et al. ${ }^{26}$ However, these authors concluded that differences became "inconsequential" when the definition of physical activity was broadened beyond traditional sports to include conditioning activities that are not normally regarded as "sports". This was not the case in the study reported here, where a broad definition was used.

Cycling, swimming, and running/jogging involved relatively large proportions of participants at both ages and accounted for similar proportions of total activity time. This result suggests that participation rates may be better promoted by encouraging involvement in informal individual activities rather than organised competitive sport. The total amount of time spent in swimming and cycling among $15-18$ year olds in the LINZ study ${ }^{25}$ was similar to the times reported by 15 year olds in the current study but substantially greater than the time reported by 18 year olds in our study. By aggregating data from adolescents in one category, rather than analysing by each one year age group as in the current study, the LINZ report probably masked the differences we found between younger and older adolescents.

Changes between ages 15 and 18 included (a) a reduction in the amount of time spent in physical activity and the number of activities, (b) changes in popularity of some types of activity, and (c) changes in sex differences in participation rates for some activities.

More than half the 15 year olds who spent at least four hours a week in physical activity had reduced their participation time to below this level at age 18. Four hours a week is not extreme, so this result should concern those involved in health promotion. We have shown that higher levels of fitness at age 15, higher levels of self assessed health, and playing representative school sports are all predictors of maintaining this reasonable level of activity at age 18, suggesting possible strategies for health promotion interventions. These strategies could be directed at interventions in schools such as encouraging youngsters who are not "elite" athletes to be involved in representative sports and promoting fitness through routine daily physical activity.

Biological, psychological, and developmental factors could explain the changes we observed over the three year study period, but social and organisational factors may also be implicated and these may be more amenable to change. Physical activity in late adolescence is more a matter of choice than it is at a younger age when school curricula influence activity levels. Involvement in sports and other physical activities may be difficult to arrange without the organisational support and practical encouragement provided by schools, and pressure to spend more time in work or education may diminish the priority given to physical activities. It is important that barriers to physical activity involvement are addressed in the interests of promoting healthy lifestyles in 
young adulthood and beyond. The present study represents an investigation of the natural history of participation in leisure time physical activity. As the DMHDS cohort ages, further measures should be taken to document participation and identify factors that may facilitate or bar involvement in physical activity.

We acknowledge the helpful comments of the anonymous referees. This paper was completed during tenure by the first
author of a Training Fellowship from the Health Research author of a Training Fellowship from the Health Research Council of New Zealand (HRC) and during tenure by the second author of a Postdoctoral Fellowship from the HRC. General funding for the assessment of the DMHDS cohort at age 18 years was provided by the HRC and the United States National Institute of Mental Health. The support of Dr Phil Silva, Direc-
tor of the DMHDS, is gratefully acknowledged. We thank Dr tor of the DMHDS, is gratefully acknowledged. We thank Dr Duncan McFarlane for the use of the physical activity data obtained from the DMHDS cohort at age 18 and Stephen W Marshall and Judith Smeijers for assistance with data management and cleaning. The support of the Accident Rehabilitation and Compensation Insurance Corporation (ACC) and the HRC as joint funders of the Injury Prevention Research Unit (IPRU), Department of Preventive and Social Medicine, University of Otago, is acknowledged. Thanks are also due to the interviewers and to Dianne Allnatt, Secretary IPRU, for assistance with proofreading. Last, but by no means least, thanks are due to the cohort members whose cooperation made this study possible.

1 Bernadet P. Benefits of physical activity in the prevention of cardiovascular diseases. $\mathcal{f}$ Cardiovasc Pharmacol 1995;25(Suppl 1):S9-14.

2 Jones TF. Walking to prevent heart disease. Arch Fam Med 1994;3:703-10.

3 Helmrich SP, Ragland DR, Paffenbarger RS. Prevention of non-insulin-dependent diabetes mellitus with physical non-insulin-dependent diabetes mellitus with

4 Shephard RJ, Shek PN. Cancer, immune function, and physical activity. Can f Appl Physiol 1995;20:1-25.

5 Macfarlane GJ, Lowenfels AB. Physical activity and colon cancer. Eur f Cancer Prev 1994;3:393-8.

6 Friedenreich CM, Rohan TE. A review of physical activity and breast cancer. Epidemiology 1995;6:311-17.

7 Greendale GA, Barrett-Connor E, Edelstein S, et al. Lifetime leisure exercise and osteoporosis: The Rancho Bernardo Study. Am f Epidemiol 1995;141:951-9.

8 Weyerer S, Kupfer B. Physical exercise and psychological health. Sports Med 1994;17:108-16.

9 Mackenbach J, van der Mheen H, Stronks K. A prospective cohort study investigating the explanation of socio- economic inequalities in health in the Netherlands. $S o c S_{c i}$ Med 1993;38:299-308.

10 Blaxter M. Health and Lifestyles. Tavistock: Routledge, 1990

11 Statistics New Zealand, Ministry of Health. A Picture of Health. Wellington: Department of Statistics, Ministry of Health, 1993.

12 van der Lucht $\mathrm{F}$, Groothoff J. Social inequalities and health among children aged $10-11$ in the Netherlands: causes and consequences. Soc Sci Med 1995;40:1305-11.

13 Keays JJ, Allison KR. The effects of regular moderate to vigorous physical activity on student outcomes: a review. Can f Public Health 1995;86:62-5.

14 Dishman RK, Sallis JF, Orenstein DR. The determinants of physical activity and exercise. Public Health Reports 1985;100:158-71

15 Maskill C. A health profile of New Zealand adolescents. Wellington: Department of Health, 1991. (Health Research Services discussion paper 14)

16 Benedict V, Lundeen K, Morr B. Self assessment by adolescents of their health status and perceived health needs. Health Values: Achieving High Level Wellness 1981;5:239-45.

17 Sweeting H. Reversals of fortune? Sex differences in health in childhood and adolescence. Soc Sci Med 1995;40:77-90.

18 Reeder AI, Stanton WR, Langley JD, Chalmers DJ. Adolescents' sporting and leisure time physical activities during their 15th year. Can $\mathcal{F}$ Sports Sci 1991;16:308-15.

19 Donovan J, Jessor R, Costa F. Structure of health-enhancing behavior in adolescence: a latent-variable approach. $\mathcal{f}$ Health Soc Behav 1993;34:346-62.

20 Silva PA. The Dunedin Multidisciplinary Health and Development Study: a 15 year longitudinal study. Paediatr Perinat Epidemiol 1990;4:76-107.

21 Reeder AI, Feehan M, Chalmers DJ, Silva PA. Some socioeconomic characteristics of a much-studied cohort: the Dunedin Multidisciplinary Health and Development Study. New Zealand fournal of Educational Studies 1994;29: 209-13.

22 Taylor H, Jacobs D, Schucker J, et al. A questionnaire for the assessment of leisure time physical activities. Fournal of Chronic Diseases 1978;31:741-55.

23 American College of Sports Medicine. Position statement on the recommended quantity and quality of exercise for developing and maintaining fitness in healthy adults. Sports Medicine Bulletin 1978;13:1-4.

24 Brunswick AF. Health needs of adolescence: how the adolescent sees them. Am 7 Public Health 1969;59:173045.

25 Cushman G, Laidler A, Russell D, et al. Life in New Zealand Commission Report Volume IV: Leisure. Dunedin, New Zealand: University of Otago, 1991.

26 Stephens T, Jacobs DR, White CC. A descriptive epidemiology of leisure-time physical activity. Public Health Rep 1985;100:147-58. 